\title{
THE CONSUMER CONFIDENCE REPORT - A TOOL FOR DEVELOPING MARKETING STRATEGIES DESIGNED FOR THE ONLINE ENVIRONMENT
}

\author{
Mircea Fuciul \\ Luigi Dumitrescu ${ }^{2}$
}

\begin{abstract}
The consumers are the backbone of all marketing strategies, decisions and actions, but at the same time, it has become extremely important to gain and keep the consumers happy and close to your company, brand or product. Our paper aims to present an important marketing tools that the companies and their management teams can use to develop marketing strategies designed for the online environment of the $21^{\text {st }}$ Century: the consumer confidence report. We are presenting the main tools developed for creating such a report: Consumer Confidence Index (CCI) and The Michigan Consumer Sentiment Index (MCSI), their advantages and disadvantages. We will present the manner in which we can use the consumer confidence report to develop new marketing strategies for the next period of time. The paper also underlines a statistical analysis of the consumer confidence reports for eastern and south-eastern European countries for the 2010 - 2016 timeframe. We point out the main reasons for the differences between the figures and these countries considering their demographical profile.
\end{abstract}

Keywords: consumers, confidence report, index, strategies, marketing

JEL Classification: G00, C10, M30, M31

\section{Introduction}

The consumers and how they buy have changed drastically in the last decades or more, but at the same time we must take into account how the world of marketing has changed in these decades or better said in the last century or so. Before delving into the main subject of this paper, we must be aware of the great changes that have taken place in the world of marketing and also in the manner in which the consumers regard and act in the process of buying goods and services.

As we know over the course of the last century, the marketing concept and activity has changed and evolved greatly, from the (King in Schwartz, 1965) production oriented marketing of the 1900 to the 1930s', the sales orientation of the 1930s' to the 1950s' and, starting with the modern marketing orientation from the beginning of the 1950s, the marketing practice has arrived to the stage of societal marketing and that of the holistic marketing concept presented by the well-known professor Philip Kotler in his by now known Marketing Management book (Kotler and Keller, 2008, pp. 17-20).

But even Kotler's presentation of the evolution of marketing has evolved with the times, when in his Marketing 3.0 and Marketing 4.0 books, he realigns the evolution of the marketing concept and practice in accordance with the new digital information age, by presenting three stages (Kotler et. al, 2010; Kotler et. al., 2017): marketing 1.0 - which represents the production and product oriented marketing, where the consumer could not choose a product, he could only buy what the supplier offers; marketing 2.0 - consumer and human centred marketing, where the customer is king and they can choose from a wide variety of products, serviced of characteristics;

\footnotetext{
${ }^{1}$ Assist. Prof., Ph.D., Romanian-German University of Sibiu, Faculty of Economics, Email: mirceafuciu@yahoo.com

${ }^{2}$ Prof., Ph.D.,’Lucian Blaga” University of Sibiu, Faculty of Economics, Email: dumitresculuigi@yahoo.com

DOI: 10.29302/oeconomica.2017.19.2.3
} 
marketing 3.0 - represents the value driven era and according to this evolution of the concept, the consumers are not just customers, they are being treated as individuals with minds, hearts and souls. The consumers are looking for something deeper: the emotional and spiritual fulfilment in the products and services that they choose. Last, but not least is the marketing 4.0 era - which takes on a deeper journey into the human and consumer oriented marketing taking into account the technological advancements and the convergence of this field towards the "sharing" economy, the "now" economy, omni-channel integration, content marketing, social media marketing, social CRM etc.

So as we can see, we find ourselves into a new and global economy, directed by the consumer, by their needs and their desires, by the informational connectivity between the producers and their clients, and by the changing of cultures and subcultures based on the evolution of information and communication technologies. In this setting we consider that the consumer confidence in their favourite products, services or brands must not weaver. Therefore, the consumer confidence reports can be a viable tool for multinationals, for SMEs and for all the players in an economy, to use in their best interest in order to develop and improve their online and offline marketing strategies for the long term.

\section{Consumer confidence in an ever-changing economy}

The economic system is changing all the time. The last decade has represented a trial for the economic development of our country and for the neighbouring countries. The $2008-2009$ financial crisis represents the most important economic crisis that the world has faced since the great depression of the 1929 - 1933 period. Such a difficult time for companies and consumers meant a" catastrophic collapse in confidence" (Stiglitz, 2008 in Dees and Brinca, 2013).

Such events usually lead to changes in the consumer confidence for certain goods, services, brands and even economies. Confidence in general and consumer confidence in particular are subject to increasing interest by many agents, including central banks and governments at the national level, and supranational entities, such as the European Commission of the European Union (Ramalho et.al., 2011). But what represents the consumer confidence? A simple definition of the consumer confidence states that it represents a "statistical measure of consumers' feelings about current and future economic conditions, used as an indicator of the overall state of the economy" (Oxford Dictionaries, 2017).

Understanding this concept has become extremely important for governments, multinationals, SMEs and for their managers or leaders. It has become increasingly obvious that the consumer confidence is shifting on a monthly basis and it has become more visible on a yearly basis. Following the evolution of such a statistical indicator can help those interested in making the right decisions at the right time.

But is there a clear connection between confidence as a holistic concept and the process of economic decision? Dees and Brinca state that there are two aspects that have to be taken into consideration from a theoretical point of view when we are discussing this concept (Dees and Brinca, 2013):

a) the literature has concentrated on the conceptualization of confidence and its role in modern theories of consumption. If consumers were to behave according to the Permanent Income Hypothesis (PIH), no information known to the consumer when the consumption choice was made could have any predictive power for how consumption will change in future periods (Hall, 1978). All the changes in relation to the PIH can be justified as money problems of the consumers. But these money problems can have different causes, other that the economical ones, such as wars or political tensions / civil unrest that can make the consumer choose wisely what and when to buy or not to buy (Acemoglu and Scott, 1944 in Dees and Brinca, 2013).

b) For an empirical view point, the literature has been concerned with whether or not confidence indicators contain any information beyond economic fundamentals. The concern is 
whether confidence can be explained by current and past values of variables such as income, unemployment, inflation or consumption or, in other way, whether confidence measures have any statistical significance in predicting economic outcomes once information from the above mentioned variables are used. (Dees and Brinca, 2013)

According to Rene Segers, most industrialized countries report such indicators at a monthly level. Typically, consumer confidence is measured by surveying one thousand or more individuals each month. The individuals are asked whether they believe that their situation has improved in the previous period or will improve in the next period, while focusing on their financial situation, employment, and, for example, their purchases of durable and more expensive products in particular. (Segers et. al, 2017).

The level of consumer confidence in one's economy is assessed with the help of several statistical indicators or indexes like: the consumer confidence index (CCI); the Michigan Consumer Sentiment Index (MCSI); the European sentiment indicator (ESI) and other such indicators that are usually published on a monthly basis by the appropriate institutions together with other statistical indicators designed to have a better understanding of the economy.

The Consumer Confidence Index ${ }^{\circledR}$ represents "a barometer of the health of the U.S. economy from the perspective of the consumer. The index is based on consumers' perceptions of current business and employment conditions, as well as their expectations for six months hence regarding business conditions, employment, and income. The Consumer Confidence Index and its related series are among the earliest sets of economic indicators available each month and are closely watched as leading indicators for the U.S. economy" (Conference Board, 2017).

The Consumer Confidence Index ${ }^{\circledR}$ is calculated by determining the percentage of the positive responses and comparing those values to the benchmark values from 1985 (when the index started. As stated before the CCI measures the degree of optimism that the consumers have about the economy and what their financial state is. It is a known fact that, if the consumers feel optimistic about their income or are certain about further personal or family income increase in the present or the near and distant future, they usually spend more, they go out more and add to the economy.

At the same time, we must be aware that the CCI is a survey based indicator that comes from the Consumer Confidence Survey and every survey has a certain dose of subjectivity, the consumers are prone to overreaction to some aspects of the economy, and their responses will usually reflect that. Another aspect that has to be underlined is that the CCI is a lagging indicator based on the opinions of the individuals about events and changes that have occurred.

Only in recent years, the CCI has been comprised of two general aspects, each with their set of questions: (1) Present situation index - with regard to the present business conditions, employment conditions; and (2) Expectation index - regarding the next 6 months for: business conditions, employment conditions; total family fix income.

The Michigan Consumer Sentiment Index (MCSI) is similar to the Consumer Confidence Index, but is calculated using telephoned surveys to gather information on the consumers' expectation with regard to the economy. Being published on a monthly basis, it represents a method by which the companies, the investors can have a clear image of the overall economy and also shows if and weather the consumer want to spend money (Investopedia, 2017).

According to Investopedia (2017), the Consumer Sentiment is a "statistical measurement and economic indicator of the overall health of the economy as determined by consumer opinion. Consumer sentiment takes into account an individual's feelings toward his or her own current financial health, the health of the economy in the short term and the prospects for longer term economic growth".

The Index of Consumer Sentiment (ICS) is "compute the relative scores (the percent giving favourable replies minus the percent giving unfavourable replies, plus 100) for each of the five index questions $(\mathrm{x} 1 \ldots \mathrm{x} 5)$. Round each relative score to the nearest whole number. Using the 
formula shown below, sum the five relative scores, divide by the 1966 base period total of 6.7558 , and add 2.0" (University of Michigan, 2017).

The Michigan Consumer Sentiment Index is published by the University of Michigan survey of consumers, and as stated before, they publish on a monthly basis the following indexes: the index of consumer sentiment, the index of consumer expectations and the current economic conditions index.

The index of consumers' expectations is the main index published U.S. Department of Commerce, Bureau of Economic Analysis and it includes the following areas: (1) how consumers view prospects for their own financial situation, (2) how the respondents view prospects for the general economy over the near term, and (3) how the consumers view the prospects for the economy over the long period of time (University of Michigan, 2017). The index of consumer expectations is issued on a monthly basis and it contains 50 core questions, each of them based on different aspects of consumers' attitudes and expectations. According to the university of Michigan website (2017), the index of consumer sentiment is used as a base to measure and monitor the consumer sentiment by countries such as: Austria, Australia, Belgium, Canada, Denmark, Finland, France, West Germany, Great Britain, Greece, Ireland, Italy, Japan, Luxembourg, Norway, Spain, Sweden, Switzerland, and Taiwan.

At the level of the European Union, the Eurostat (2017) uses the economic sentiment index (ESI), which is a composite indicator made us of five confidence indicators that have the following input within the ESI: industrial confidence indicator $(40 \%)$; construction confidence indicator $(5 \%)$; services confidence indicator (30\%); consumer confidence indicator $(20 \%)$; retail trade confidence indicator $(5 \%)$.

Taking all these elements into account the usage of these indexes can have a real impact on the economic policy making and at the same time it can be used by marketing and communication specialists. If the economic optimism or the questions regarding the respondents views of the future economic developments of their country can be viewed as a disadvantage by the marketing specialists, the main advantages of using such indexes and indicators is that its offers to the specialists information regarding: house acquisitions and / or household durables; acquisition of financial assets; decision making within the families; timing of the acquisition making process; the consumers perception regarding the current and future prices; evolution of the individual or household income etc.

If the marketing managers and marketing specialists can access and use this information, if they make in-depth analysis of the various components of the indexes or indicators, the companies can and must develop marketing strategies based on them. At the same time, the fact that we live in a global economy and in the age of worldwide communication methods, these indexes or indicators can be analysed for different countries (see the Eurostat statistics of the ESI, which shows the evolution of the index and its components for different countries of the EU).

The fact that the indicators are published by recognised bodies for different countries gives the companies the possibility to assess and prepare for the entrance of the economical entities in the targeted countries and their markets. Such indicators can provide a clear profile of the consumption process, of the consumers' potential needs and of the economical environment of this country.

\section{Statistical data about the consumer confidence indicators}

The Nielson company publishes the quarterly consumer confidence reports, about the optimism or pessimism of the survey participants regarding the state of their economy. In the first figure we can see he consumer confidence in the first quarter of the period between 2010 and 2016. 
We have chosen several central and eastern European countries to view the evolution of the consumer confidence in these countries.

The consumer confidence is measured around the level of 100: if the consumer confidence level is below 100 than the consumers are pessimistic and if the level is above 100, then the consumer are optimistic about their economies.

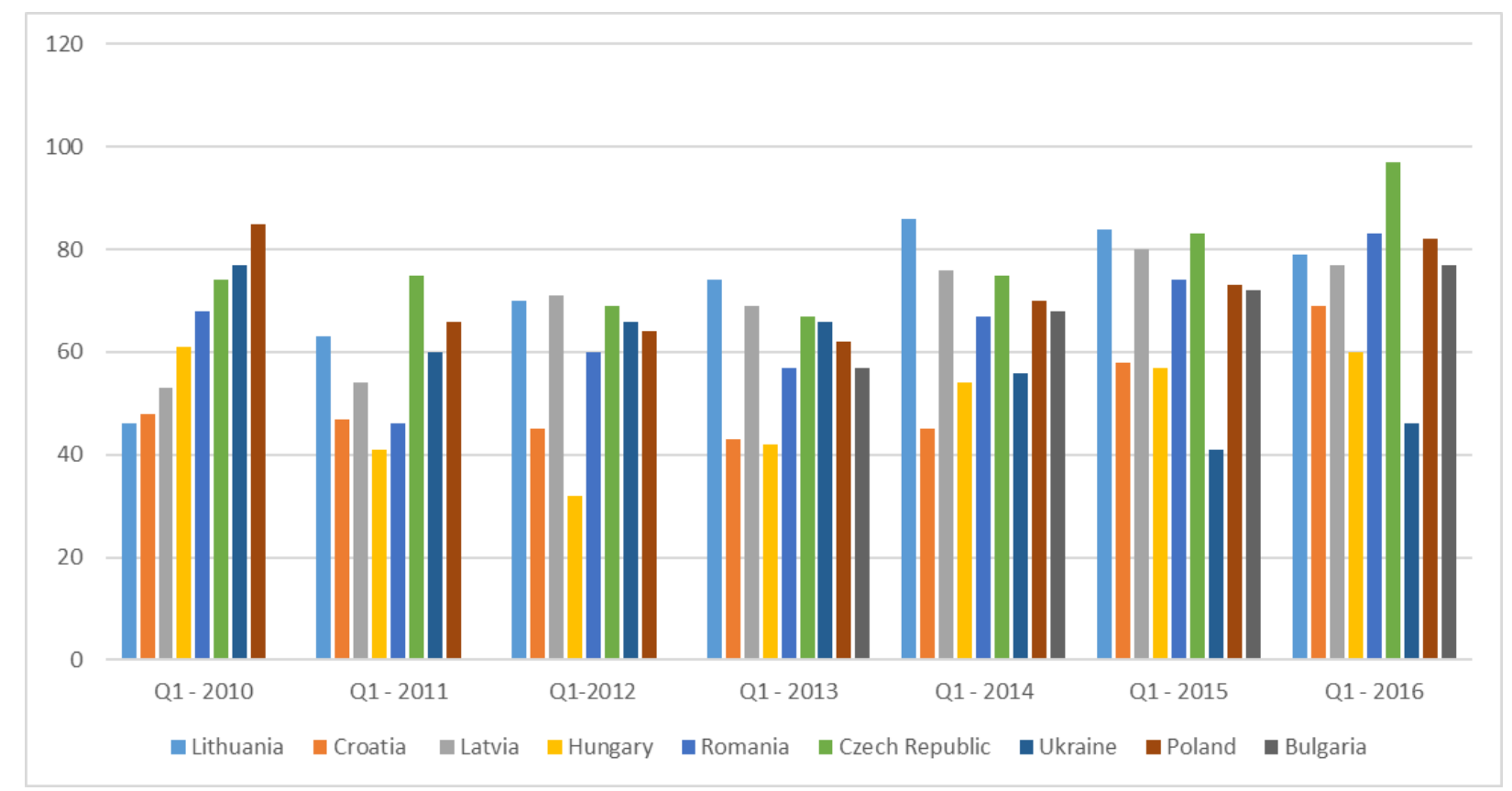

Figure no. 1. Consumer confidence in Q1 (2010 - 2016)

Source: author's computation using Nielsen Company data

As we can see from the above presented figure, the consumer confidence varies from year to year, in 2010 the country with the lowest confidence level is Lithuania, with 46 and the highest is Poland with 85. Romania is positioned at 68, above the average for these countries at 64 for 2010.

The lowest levels were registered in the first quarters of 2011 and 2012, when the effects of the $2008-2010$ economic crisis is felt in these countries. We see for example the case of Romania with a drop in the consumer confidence from 68 in the year 2010 to 46 in 2011 and an increase at 60 in the year 2012. This drop of almost $33 \%$ is the biggest drop in confidence for the analysed countries.

We can also see that the last two years taken into evaluation, 2015 and 2016 have offered a boost in confidence for the consumers, all the countries (including Bulgaria, which is part of our analysis since 2013) have registered an increase all across the board.

The second part of our analysis (figure no. 2) stands for the evolution of the same consumer confidence reports for the fourth quarter of the 2010 - 2016 time frame in the same countries. Figure no. 2, shows the evolution of the $4^{\text {th }}$ Quarter provided by the date of the Nielson Company. The analysis shows that the phenomenon seen in the $1^{\text {st }}$ Quarter is present also in this second part of our research.

The overall levels of confidence are below the 100 mark, which means a level of pessimism within the population, but are increasing in the last four years of our analysis and in 2016, the Czech Republic passes above the 100 points of consumer confidence which shows a level of optimism within the population about their future. 


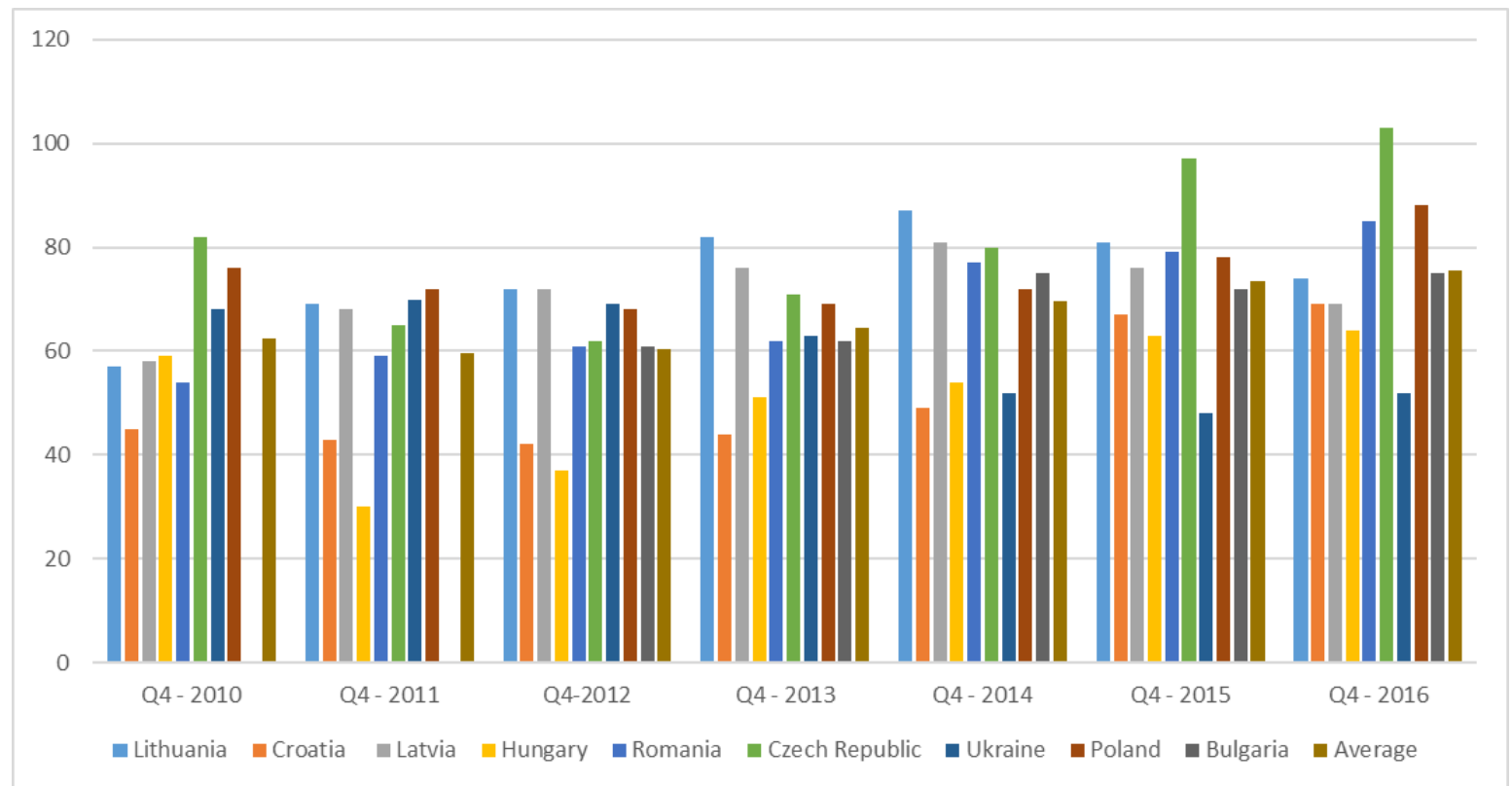

Figure no. 2. Consumer confidence in Q4 (2010 - 2016)

Source: author's computation using Nielsen Company data

As stated in the first part of our paper, the University of Michigan releases on a monthly basis the Index of Consumer Sentiment. In figure 3, we can see the evolution of this index for the last 10 years, considering 1996 as base value of 100 .

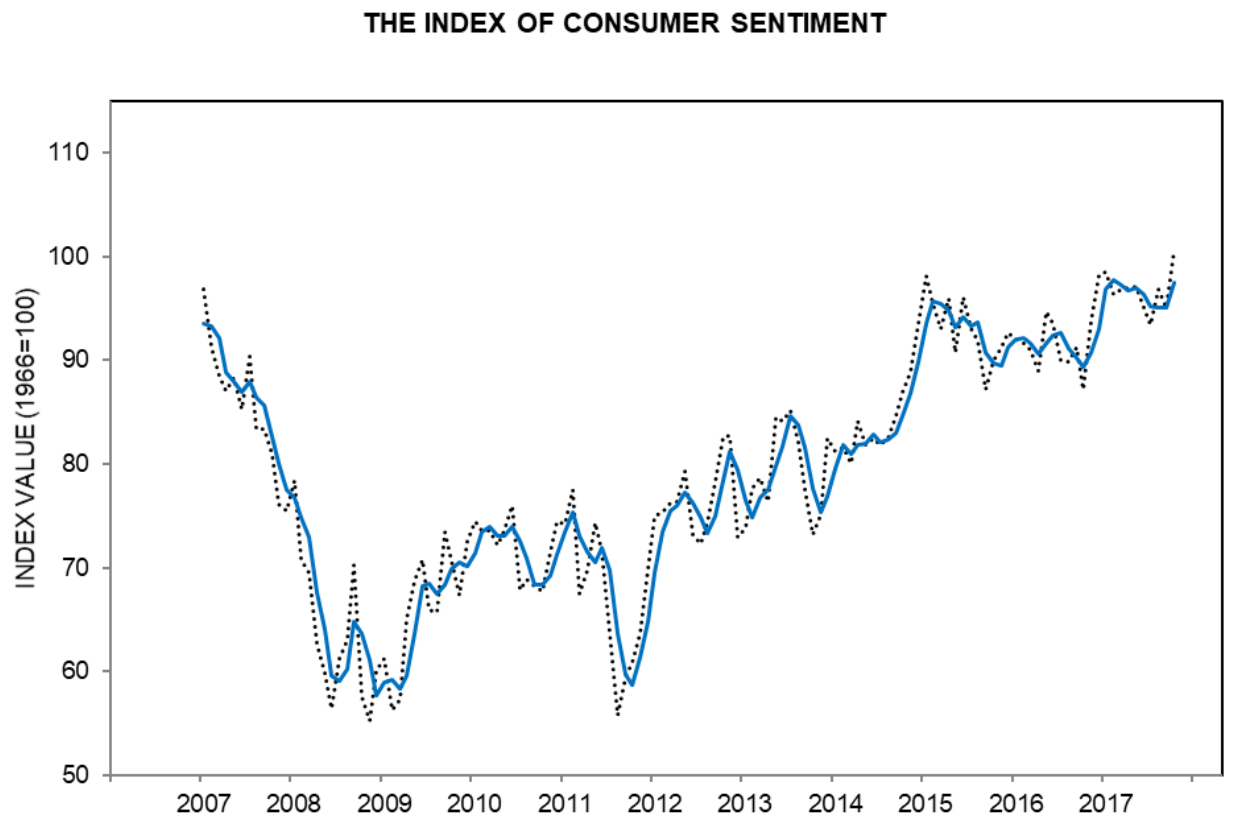

Figure no. 3. Index of Consumer Sentiment (2007 - 2017)

Source: http://www.sca.isr.umich.edu/charts.html

It is a known fact that the Index of Consumer Sentiment is released for the North American Market, and this is clearly viewed in the above presented figure 3, which shows the evolution and subsequent decrease in confidence level in the 2008 - 2009 period, the initial years of the financial crisis of the subprime mortgage market in the United States that has developed into a full blown 
global "pandemic" that resulted in the bankruptcy of important financial players like the Lehman Brothers and other financial institutions were in trouble (Merrill Lynch; Washington Mutual; Fannie Mae; Freddie Mac etc). The DowJones Index has gone down from more than 14000 points in 2007 to around 6600 points in the spring of 2009.

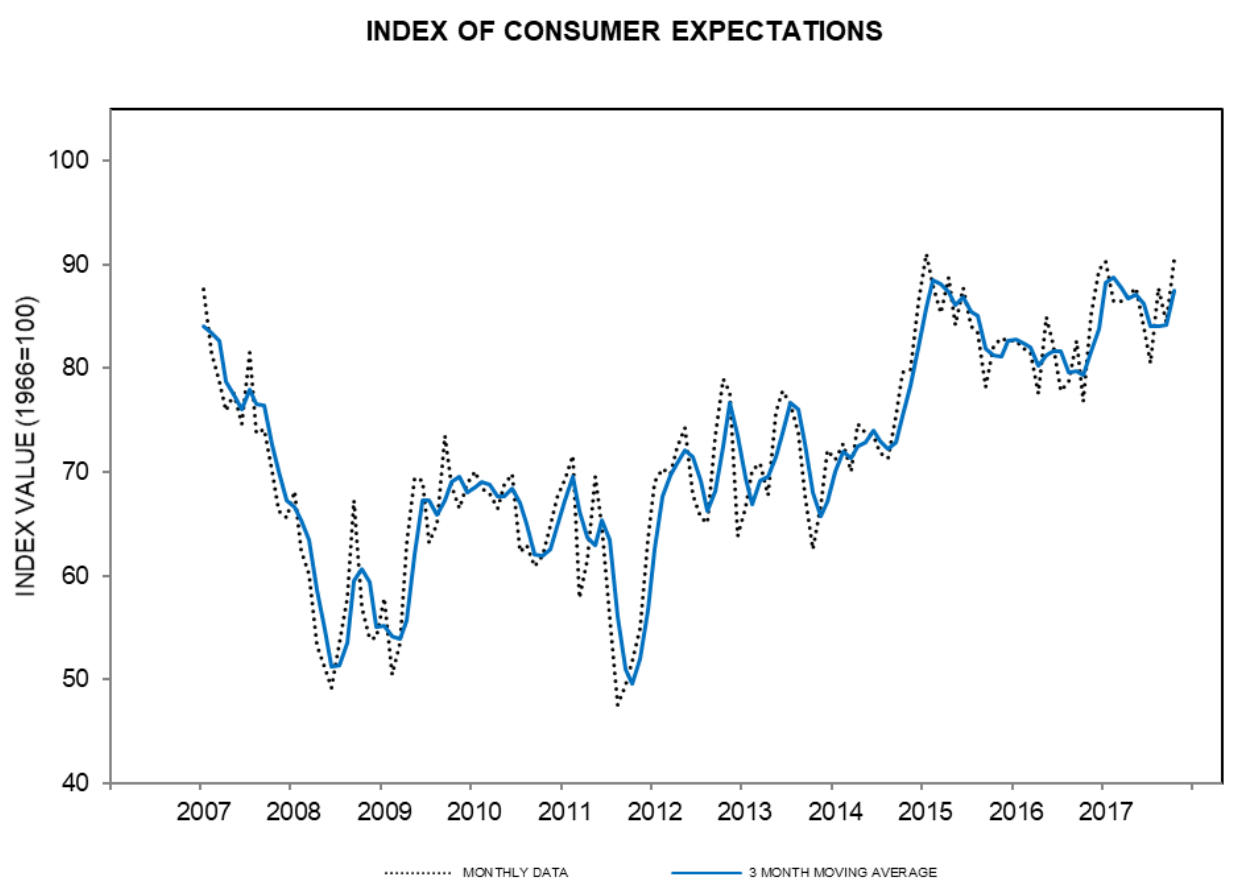

Figure no. 4. Index of Consumer Expectations (2007 - 2017)

Source: http://www.sca.isr.umich.edu/charts.html

Figure no. 4 shows the evolution of the Index of Consumer Expectation, the most important index published by the University of Michigan, over the last 10 years. As we can see, if we match the $3^{\text {rd }}$ and $4^{\text {th }}$ figure, we can observe that the drops in expectations and in sentiments have happened in the same periods of time (2008 - 2009 and between 2011 - 2012). Although these data match from a decreasing and increasing point of view, we can clearly see that the consumer expectations are lower (about 10 points) than the consumer sentiment index levels.

At the same time, the major fluctuations of the consumer confidence indicators or indexes is also governed by the evolution of the politics or the existence of a political crisis or that of political uncertainty in the analysed countries. We also have to acknowledge that the index of consumer sentiment and the index of the consumer expectations is provided and analysed for the North American Market, which has certain particularities from the South and Eastern European area.

\section{Conclusions}

By developing this paper, we hope that we are bring forth an economical and a financial tool that can be used by the companies, their managers and the marketing specialists, to assess the economic and consumption environment. The development and publishing of these indicators has become in indispensable tool for the financial markets, that must be used in order to develop marketing strategies for the online and the offline environment. These indicators, by their composition show that market information and data can be gathered in order to develop new marketing strategies for the 21 st century consumers.

Weather we talk about developing the activity on the current market or by entering a new market, we have to take into account these financial tools that can become environmental marketing tools. The fact that the consumer has changed in the last decade or more, and has become a global 
consumer, in the face of fierce competition, the marketers must adapt their marketing activities, their strategies to fit these consumers, their needs and desires, to fight the threats of the competition etc., by having access to marketing tools that can give the extra edge.

The consumer confidence index (CCI), the Michigan Consumer Sentiment Index, the Michigan Consumer Expectation Index and the European Sentiment Index (ESI) can and must become tools for the marketers and their companies in the analysis of future and current markets, on their analysis of potential fields of activity and that of the international development of marketing.

The ups and downs of these indicators or indexes show clear issues that can influence the activity of the company, either from a micromarketing level (clients, competition, suppliers etc.), but also at a macromarketing level (socio-cultural stage; economical and demographical stage; legal and political issues and influences). All these can point the company, their analysts, the decision makers towards the best investment, decision to enter or withdraw form a market etc.

We acknowledge the limitations of this paper and we consider that further study must be carried out in order to identify if and how the consumer confidence indexes, reports or indicators can be used by marketers in order to further understand the market and their clients at a national or international level.

\section{References:}

1. Acemoglu D, Scott A. (1994), Consumer confidence and rational expectations: are agents beliefs consistent with the theory? The Economic Journal, issue 104, pp. 1-19.

2. Balaure, V. (coord.), 2002, Marketing, Uranus Publishing House, Bucharest p. 45-46

3. Hall R.E. (1978), Stochastic implications of the life-cycle / permanent income hypothesis: theory and evidence. Journal of Political Economy issue 96, pp .971-987.

4. King, R., (1965), The marketing concept, in Schwarz, G., (ed.), Science in marketing, John Wiley and Sons, New York, 1965, citation by Balaure, V. (coord.), 2002, Marketing, Uranus Publishing House, Bucharest p. 45-46.

5. Kotler, Ph., Keller, K.L., 2008, Marketing Management, $5^{\text {th }}$ Edition, Teora Publishing House, Bucharest, 2008;

6. Kotler, Ph., Kartajaya, H., Setiawan, I., 2010, Marketing 3.0 - from products to consumers to the human spirit, John Wiley and Sons Inc., Hoboken, New Jersey, USA;

7. Kotler, Ph., Kartajaya, H., Setiawan, I., 2017, Marketing 4.0 - from traditional to digital, John Wiley and Sons Inc., Hoboken, New Jersey, USA

8. Ramalho, E.A., Caleiro, A., Dionfsio, A., 2011, Explainig consumer confidence in Portugal, Journal of Economic Psychology, 32 (2011), doi:10.1016/j.joep.2010.10.004, pp. 25 - 32.

9. Segers, R., Franses, P.H., Bruijn, B.d., (2017), A novel approach to measure consumer confidence, Econometrics and Statistics, 4 (2017), http://dx.doi.org/10.1016/j.ecosta.2016.11.009, pp. $121-129$.

10. Stiglitz, "The fruit of hypocrisy", The Guardian, 16 September 2008, http://www.guardian.co.uk/commentisfree/2008/ in Dees, S., Brinca, P.S., 2013, Consumer confidence as a predictor of spending: Evidence for the United States and the Euro area, International Economics, 134 (2013), http://dx.doi.org/10.1016/j.inteco.2013.05.001, pp. 114

11. *** Oxford Dictionaries, https://en.oxforddictionaries.com/definition/consumer confidence, accessed on October $15^{\text {th }}, 2017$.

12. *** The Conference Board, https://www.conference-board.org/pdf_free/press/ TechnicalPDF_4134_1298367128.pdf, accessed on October $15^{\text {th }}, 2017$.

13. *** http://www.investinganswers.com/financial-dictionary/economics/consumerconfidence-index-cci-339, accessed on October 15 ${ }^{\text {th }}, 2017$.

14. *** http://www.investopedia.com/terms/m/mcsi.asp, accessed on October $15^{\text {th }}, 2017$.

15. *** https://data.sca.isr.umich.edu/survey-info.php, accessed on October $15^{\text {th }}, 2017$. 
16. $* * *$ https://data.sca.isr.umich.edu/fetchdoc.php?docid=24770, accessed on October $15^{\text {th }}$, 2017.

17. *** http://ec.europa.eu/eurostat/statistics-explained/index.php/Glossary:Confidence indicator, accessed on October $15^{\text {th }}, 2017$. 